Bangladesh J. Pl. Breed. Genet., 30(1): 11-20, 2017

\title{
GENETIC DIVERSITY INAUS RICE LANDRACES OF BANGLADESH USING SSR MARKERS
}

\author{
M. Khalequzzaman, M. Z. Islam, M. A. Siddique, M. F. R. K. Prince, E. S. M. H. \\ Rashid and M. S. Ahamed
}

\author{
Genetics Resources and Seed Division \\ Bangladesh Rice Research Institute \\ Gazipur 1701, Bangladesh
}

\begin{abstract}
Assessment of genetic diversity is essential for germplasm characterization, utilization and conservation. Genetic diversity of 31 Aus rice landraces of Bangladesh was assessed using 36 SSR (simple sequence repeats) markers. A total of 141 alleles were detectedand the number of alleles per locus ranged from two (RM1216, RM145, RM282, RM293, RM567and RM496) to 10 alleles (RM304), with an average of 3.92. The gene diversity varied from 0.06 (RM145) to 0.80 (RM304) with an average of 0.54 and the PIC values ranged from 0.06 (RM145) to 0.78 (RM304), with an average of 0.48.PIC value revealed that RM304 was the best marker for characterizing the studied Aus rice genotypes. The dendrogram from unweighted pair-group method with arithmetic average clustering of markers classified the genotypes into five major groups with a coefficient of 0.49 . Two and three dimensional graphical views of Principal Coordinate Analysis (PCA) revealed that the genotypesHashikalmi, Chaina, Puitraaijang, Saithsail, Kuchmuch, Kalodhan, Ausdhan and Itcriewere found far away from the centroid of the cluster and can be selected as parents for further breeding programs. The results provided some useful implications for establishment of sovereignty of Bangladeshi rice gene pool. This information will provide maximum selection of diverse parents, background selection during backcross breeding programs and assist in broadening germplasm-based rice breeding programs in future.
\end{abstract}

Keywords: Aus rice, landraces, cluster analysis, SSR, yield.

\section{INTRODUCTION}

Rice (Oryza sativa L.) is an important cereal crop grown exclusively for human consumption that is the staple food for about $50 \%$ of the world population (Garriset al., 2005; Ramkumaret al., 2010). Now, $90 \%$ of world rice is produced in Asia on an area of almost 150 million hectares. Rice accounts for $50 \%$ of agricultural income in Asia and supplies almost 80 percent of the region's nutrition. In Bangladesh, rice engages more than $70 \%$ of the rural population and is central to agriculture and the national economy. At present, rice alone constitutes about $93 \%$ of the total food grains produced annually in the country (BER, 2013). It provides about $62 \%$ of the calorie and $46 \%$ of the protein in the average daily diet of the people (HIES, 2010). Rice genetic resource is the primary material for rice breeding and makes a concrete contribution to global wealth creation and food security (Zhang et al., 2011). Rice landraces contain greater genetic diversity than elite cultivars (Londoet al., 2006). However, Bangladesh had abundant rice 
germplasm from time immemorial. But the ongoing rapid changes in agricultural practices that favoragronomically improved varieties have become a serious threat for the persistence of indigenous rice varieties in Bangladesh. Besides, various interventions of rice habitat are occurring due to over population. Thus, conservation and management strategies are urgently needed to prevent further loss of genetic diversity inherent to indigenous rice varieties in the country. Therefore, rice landraces need to exploit in hybridization programme for maintaining total rice gene diversity.

Exploring diversity in the landrace collection and characterization is very essential for identifying new genes and further improvement of the germplasm (Thomson et al., 2007). In Bangladesh, variety identification and diversity analysis has been done mostly through morphological descriptors and limited at molecular level. Due to stage specific expression of characters and influence of environment; morphological diversity estimates are less reliable. Moreover, at times there may be little morphological diversity among cultivars with related pedigrees. Uses of molecular markers are considered best for analysis of genetic diversity and varietal identification since there is no effect of stage of development, environment or management practices. Availability of a large number of polymorphic markers enables precise classification of the cultivars and germplasm collections.

Molecular markers are powerful tools for evaluation of genetic diversity within and among varieties. Among various PCR-based markers, microsatellites (SSRs) are more appropriate and successfully used for assessing genetic diversity among closely related rice cultivars compared to other molecular markers; because it can be simply amplified by PCR reaction, abundant, highly informative, mostly mono locus, co-dominant, easily analyzed, cost effective and it can identify higher degree polymorphism in rice (Siddiqueet al., 2016). Microsatellites are abundant and well distributed throughout the genome in rice (Akagiet al., 1996; McCouchet al., 1997). The present study was, therefore, undertaken to investigate the genetic diversity of 31 Aus rice landraces using SSR markers.

\section{MATERIAL AND METHODS}

\section{a) Rice materials}

Thirty oneAusrice genotypes (Table 1) were studied in the Molecular Laboratory of Genetic Resources and Seed Division of BRRI during 2015 for diversity analysis. Five grams seeds from each of the entry was germinated and then sown in the earthen pots.

\section{b) SSR Markers}

Thirty six SSR primers distributing across the 12 chromosomes and covering the whole genome were used for diversity analysis.

\section{c) Genomic DNA isolation and PCR amplification}

DNA was extracted from young leaves of 14-day-old plants following the Miniscale method (Zhenget al., 1995). The total PCR reaction volume was $10 \mathrm{~L}$, composed of 3.0

L genomic DNA, $1.0 \mathrm{~L}$ of $10 \times$ PCR buffer $\left(\mathrm{MgCl}_{2}\right.$ free $), 1.35 \mathrm{~L}$ of $25 \mathrm{mmol} / \mathrm{L}$ $\mathrm{MgCl}_{2}, 0.2 \mathrm{~L}$ of $10 \mathrm{mmol} / \mathrm{L}$ dNTPs, $0.5 \mathrm{~L}$ of $10 \mathrm{~mol} / \mathrm{L}$ forward and reverse primers, $0.02 \mathrm{~L}$ of $5 \mathrm{U} / \mathrm{LTaqDNA}$ polymerase and $3.43 \mathrm{~L}$ sterile deionized water. The temperature profile was an initial denaturation step for $5 \mathrm{~min}$ at $94{ }^{\circ} \mathrm{C}$, followed by 35 cycles of denaturation $\left(94^{\circ} \mathrm{C}\right)$ for $45 \mathrm{~s}$, annealing $\left(55^{\circ} \mathrm{C}\right.$ or $\left.61^{\circ} \mathrm{C}\right)$ for $45 \mathrm{~s}$ and primer elongation $\left(72{ }^{\circ} \mathrm{C}\right)$ for $1.3 \mathrm{~min}$ and then a final extension at $72{ }^{\circ} \mathrm{C}$ for $7 \mathrm{~min}$. 


\section{d) Electrophoresis and visualization of amplified products}

The $10 \mathrm{~L}$ of PCR product with $2 \mathrm{~L}$ of a loading dye was analyzed using $8 \%$ polyacrylamide gel electrophoresis in $1 \times \mathrm{TBE}$ buffer at $75 \mathrm{~V}$ for about $2.0-2.5 \mathrm{~h}$ depending upon the allele size. The gels were stained with ethidium bromide solution $(0.5 \mathrm{mg} / \mathrm{mL})$ for $25 \mathrm{~min}$ and exposed to UV light using the molecular Imager gel documentation unit (XR System, Uvitec Cambridge, France) for visualization.

\section{e) Allele scoring and data analysis}

The size of the band for each marker was scored by AlphaEaseFC 4.0 software. The summary statistics, including the number of alleles, major allele size and frequency, gene diversity and polymorphism information content (PIC) value, were determined using PowerMarker version 3.25 (Liu and Muse, 2005). For the unrooted phylogenic tree, genetic distance was calculated using the "C.S. Chord 1967" distance (Cavalli-Sfoza and Edwards, 1967) followed by phylogeny reconstruction using neighbor-joining as implemented in PowerMarker with tree viewed using Treeview (Page, 1996). The allele frequency data from Powermarker was used to export the data in binary format (allele presence="1" and allele absence $=$ "0") for analysis with NTSYS-pc version 2.2 (Rohlf, 2002). Similarity matrix was calculated with the help of Simqual Subprogram using the Dice coefficient followed by cluster analysis with the SAHN subprogram using the UPGMA (Un-weighted pair group method using arithmetic average) clustering method as implemented in NTSYS-pc. The similarity matrix was used for principal coordinate analysis (PCA) with the DCenter, Eigen, Output, and MXPlot subprograms in NTSYSpc.

Table 1. List of Aus rice landraces with place of collections

\begin{tabular}{lll|lll}
\hline $\begin{array}{l}\text { Sl. } \\
\text { No. }\end{array}$ & Variety & $\begin{array}{l}\text { Collection } \\
\text { District }\end{array}$ & $\begin{array}{l}\text { Sl. } \\
\text { No. }\end{array}$ & Variety & $\begin{array}{l}\text { Collection } \\
\text { District }\end{array}$ \\
\hline 1 & Begun bichi & Kushtia & 17 & Raitul & Barguna \\
2 & Hashikalmi & Kushtia & 18 & Kuchmuch & Barguna \\
3 & Kalodhan & Kushtia & 19 & Puitraaijang & Barguna \\
4 & Ausdhan & Kushtia & 20 & Boula & Barguna \\
5 & Dighabawalia & Kushtia & 21 & Chaina & Barguna \\
6 & Hanuman jata & Kushtia & 22 & Saithsail & Barguna \\
7 & Itcrie & Meherpur & 23 & Sadeyaus & Barguna \\
8 & V-2 & Meherpur & 24 & Mallika & Barguna \\
9 & V-3 & Meherpur & 25 & Aduballi & Barguna \\
10 & V-4 & Meherpur & 26 & Bardhanaus & Barguna \\
11 & Parangi & Rajbari & 27 & Kaloaus & Barguna \\
12 & Sandamioni & Rajbari & 28 & Bardhanaus M-74- & Barguna \\
13 & Jaymori & Rajbari & 29 & H-171 & Barguna \\
14 & Kalohizli & Rajbari & 30 & H-12 & Barguna \\
15 & Minikit & Barguna & 31 & Kadidet & Barguna \\
16 & Parangi & Barguna & -- & -- & - \\
\hline
\end{tabular}

\section{RESULTS AND DISCUSSION}

Genetic diversity study is of prime important in conservation of endangered species and utilization of appropriate plant resources from diverse germplasm. Successful breeding 
for crop development programmes depends on genetic variability that arises from genetic diversity (Rana and Bhat, 2004). Lack of genetic variability may limit breeding progress and gain from selection. So, knowledge of the genetic diversity of any germplasm collection provides a basis for improvement of crops and development of superior cultivars. This study was investigated the allelic diversity existing among a collection of 31 Aus rice landraces from different district of Bangladesh using 36 SSR markers. SSR markers have been widely applied in the genetic diversity analysis, molecular characterization, genotypic identification and population structure estimation in several rice genetic studies including basmati rice ( Das et al., 2013; Choudhuryet al., 2013; Allhgholipouret al., 2014; Singh et al., 2013; Shah et al., 2013 and Yadavet al., 2013). In the present study, 141 alleles were detected from 36 SSR (simple sequence repeats) markers across 31 Aus rice genotypes (Table2). Similar number of microsatellite markers was previously used as subset for genetic diversity analysis of O. sativa (Garris et al., 2005; Chakrabarthia and Naravaneni, 2006; Thomson et al., 2007).Islam (2014) also detected 140 alleles with an average of 3.11 among 113 aromatic rice accessions by using SSRs. The highest amplicon size was produced by RM474 (269 bp) and the lowest by RM413 (69 bp). The highest range of band sizes was found in RM591 (252-314 bp) followed by RM454 (213-269bp) and RM496 (250-264bp), respectively. The number of alleles per locus ranged from two alleles (RM1216, RM145, RM282, RM293, RM567, RM496) to 10 alleles (RM304), with an average of 3.92. This allele is comparable to 2-9 allele per SSR locus with an average of 4.69 for various classes of microsattelite (Behera etal., 2012) and 2-7 alleles per locus as reported by Chakrabarthia and Naravaneni (2006).Our result is not fully agreement with the findings of Siddique et al, 2014, who estimated genetic diversity among T. Aman (rainfed lowland) rice germplasm collections using SSR markers.The gene diversity varied from 0.06 (RM145) to 0.80 (RM304) with an average of 0.54 and the PIC value ranged from 0.06(RM145) to 0.78 (RM304), with an average of 0.48. In general, higher PIC values were observed for SSRs having higher number of alleles. Lower PIC value indicates that the genotypes under study are closely related types, while the higher value of PIC indicates higher diversity of materials, which is better for development of new varieties. Primer RM304 had the highest PIC value (0.78) and the highest number of alleles (10) and it detected the highest level of polymorphism. Therefore, it confirmed that RM304 was the best marker for characterizing the studied Aus rice genotypes. The observed PIC values are similar to previous estimates of microsatellite analysis in rice of 0.04-0.59 (Shah et al., 2013) and 0.05-0.67 (Islam, 2014). The frequency of the most common allele at each locus ranged from $32.26 \%$ (RM474, RM334)) to $96.77 \%$ (RM145). On average, $57.55 \%$ of the31 rice genotypes shared a common major allele at any given locus.Jain et al.(2004) observed that $53.6 \%$ of 69 rice genotypes shared common alleles at any locus. Thomson et al.(2009) indicated that on an average, $62 \%$ of the 190 rice accessions of Indonesia shared a common major allele at any given of SSR locus. Similar results were also observed by others (Saini et al., 2004; Lu et al., 2005; Jayamani et al., 2007). The DNA profiles of 31 Aus rice with SSR marker RM3330 is shown in Fig. 1.

\section{Genetic distance-based analysis}

The UPGMA-based dendrogram, which was obtained from the binary data deduced from the DNA profiles of the samples analyzed, added a new dimension to the genetic similarity perspective. Five distinct groups were formed from the analysis of the pooled SSR marker data at a similarity coefficient of 0.49 . The cluster analysis showed high genetic variation among the rice cultivars studied, with similarity coefficient value ranging from 0.33 to 0.86 in SSR (Fig. 2). 
Table 2. Allele number, size and frequency, genetic diversity and PIC among 31 Aus rice genotypes for 36 SSR markers.

\begin{tabular}{|c|c|c|c|c|c|c|c|c|c|}
\hline \multirow[b]{2}{*}{$\begin{array}{c}\text { SSR } \\
\text { Marker }\end{array}$} & \multirow[b]{2}{*}{$\begin{array}{c}\text { Chro. } \\
\text { No } \\
\cdot\end{array}$} & \multirow[b]{2}{*}{$\begin{array}{l}\text { Positio } \\
\mathrm{n} \\
(\mathrm{cM})\end{array}$} & \multirow[b]{2}{*}{ Motif* } & \multicolumn{5}{|c|}{ Allele } & \multirow[b]{2}{*}{ PIC } \\
\hline & & & & No. & $\begin{array}{c}\text { Size } \\
\text { range } \\
\text { (bp) }\end{array}$ & $\begin{array}{l}\text { Size } \\
\text { (bp) }\end{array}$ & $\begin{array}{l}\text { Freq. } \\
(\%)\end{array}$ & $\begin{array}{c}\text { Gene } \\
\text { diversi } \\
\text { ty }\end{array}$ & \\
\hline RM 1 & 1 & 29.7 & (GA)26 & 5 & $132-166$ & 132 & 36.67 & 0.72 & 0.68 \\
\hline RM 151 & 1 & 36.2 & (TA)23 & 6 & $180-259$ & 180 & 53.57 & 0.62 & 0.57 \\
\hline RM 246 & 1 & 115.2 & (CT) 20 & 4 & $100-122$ & 122 & 38.71 & 0.72 & 0.67 \\
\hline RM 1216 & 1 & 132.0 & $(\mathrm{AG}) 14$ & 2 & 73-80 & 80 & 54.84 & 0.50 & 0.37 \\
\hline RM 145 & 2 & 49.8 & - & 2 & $192-196$ & 192 & 96.77 & 0.06 & 0.06 \\
\hline RM 16 & 3 & 131.5 & (TCG)5(GA)16 & 3 & $158-175$ & 175 & 35.48 & 0.66 & 0.59 \\
\hline RM 282 & 3 & 100.6 & $(\mathrm{GA}) 15$ & 2 & $134-139$ & 139 & 80.65 & 0.31 & 0.26 \\
\hline RM 487 & 3 & 127.9 & $(\mathrm{AC}) 10$ & 3 & $172-180$ & 172 & 74.19 & 0.41 & 0.37 \\
\hline RM 293 & 3 & 193.4 & (GT)20 & 2 & $209-215$ & 209 & 83.87 & 0.27 & 0.23 \\
\hline RM 554 & 3 & 100.6 & $(\mathrm{GA}) 14$ & 3 & $250-261$ & 260 & 64.52 & 0.52 & 0.46 \\
\hline RM 503 & 3 & 153.9 & (CA)59(TA)26 & 3 & $162-248$ & 248 & 90.32 & 0.18 & 0.17 \\
\hline RM 518 & 4 & 25.5 & (TC) 15 & 4 & $164-180$ & 180 & 46.67 & 0.68 & 0.63 \\
\hline RM 551 & 4 & 8.51 & $(\mathrm{AG}) 18$ & 5 & $181-207$ & 181 & 53.85 & 0.59 & 0.51 \\
\hline RM 567 & 4 & 153.6 & (GA)21 & 2 & $214-222$ & 222 & 61.29 & 0.47 & 0.36 \\
\hline RM 334 & 5 & 141.8 & (CTT) 20 & 5 & $173-195$ & 173 & 32.26 & 0.75 & 0.71 \\
\hline RM 413 & 5 & 26.7 & $(\mathrm{AG}) 11$ & 5 & $69-102$ & 69 & 45.16 & 0.66 & 0.59 \\
\hline RM 527 & 6 & 61.2 & (GA) 17 & 3 & $214-241$ & 241 & 61.29 & 0.50 & 0.40 \\
\hline RM 3330 & 6 & 61.6 & (CT) 15 & 3 & $134-148$ & 148 & 70.97 & 0.44 & 0.39 \\
\hline RM 320 & 7 & 62.5 & (AT)11GTAT(GT)13 & 4 & $186-234$ & 186 & 38.71 & 0.69 & 0.63 \\
\hline RM 542 & 7 & 34.7 & $(\mathrm{CT}) 22$ & 3 & $95-151$ & 151 & 56.67 & 0.52 & 0.41 \\
\hline RM 72 & 8 & 60.9 & (TAT)5C(ATT) 15 & 3 & $122-165$ & 165 & 87.10 & 0.23 & 0.22 \\
\hline RM 5647 & 8 & - & $(\mathrm{AAG}) 16$ & 5 & $100-149$ & 149 & 38.71 & 0.75 & 0.71 \\
\hline RM 464 & 9 & 3.3 & $(\mathrm{AT}) 21$ & 3 & $226-240$ & 240 & 84.00 & 0.28 & 0.26 \\
\hline RM 285 & 9 & 1.8 & $(\mathrm{GA}) 12$ & 3 & $143-152$ & 152 & 60.00 & 0.50 & 0.41 \\
\hline RM 304 & 10 & 73.0 & (GT)2(AT)10(GT)33 & 10 & $146-214$ & 146 & 38.71 & 0.80 & 0.78 \\
\hline RM 474 & 10 & - & $(\mathrm{AT}) 13$ & 6 & $213-269$ & 269 & 32.26 & 0.76 & 0.72 \\
\hline RM 496 & 10 & 113.0 & (TC)14 & 2 & $250-264$ & 264 & 54.84 & 0.50 & 0.37 \\
\hline RM 591 & 10 & 118.3 & (AC) 10 & 7 & $252-314$ & 252 & 48.39 & 0.70 & 0.66 \\
\hline RM 21 & 11 & 85.7 & (GA) 18 & 4 & $133-163$ & 163 & 80.65 & 0.34 & 0.32 \\
\hline RM 206 & 11 & 102.9 & (CT)21 & 5 & $130-166$ & 166 & 48.39 & 0.68 & 0.63 \\
\hline RM 224 & 11 & 120.1 & $(\mathrm{AAG}) 8(\mathrm{AG}) 13$ & 4 & $135-164$ & 164 & 70.97 & 0.45 & 0.41 \\
\hline RM 20 & 12 & - & $(\mathrm{ATT}) 14$ & 3 & $154-181$ & 154 & 51.61 & 0.57 & 0.49 \\
\hline RM 1337 & 12 & - & (AG)21 & 3 & $162-183$ & 183 & 61.29 & 0.55 & 0.49 \\
\hline RM 5364 & 12 & - & TC) 13 & 4 & $122-143$ & 143 & 41.94 & 0.66 & 0.59 \\
\hline RM 7102 & 12 & - & $(\mathrm{AGAT}) 8$ & 5 & $172-194$ & 172 & 58.06 & 0.57 & 0.51 \\
\hline RM491 & 12 & 34.3 & $(\mathrm{AT}) 14$ & 5 & $164-384$ & 164 & 38.46 & 0.73 & 0.69 \\
\hline Total & & & & 141 & & & 2071.84 & 19.33 & 17.32 \\
\hline Mean & & & & 3.92 & & & 57.55 & 0.54 & 0.48 \\
\hline
\end{tabular}

*http://www.gramene.org. 


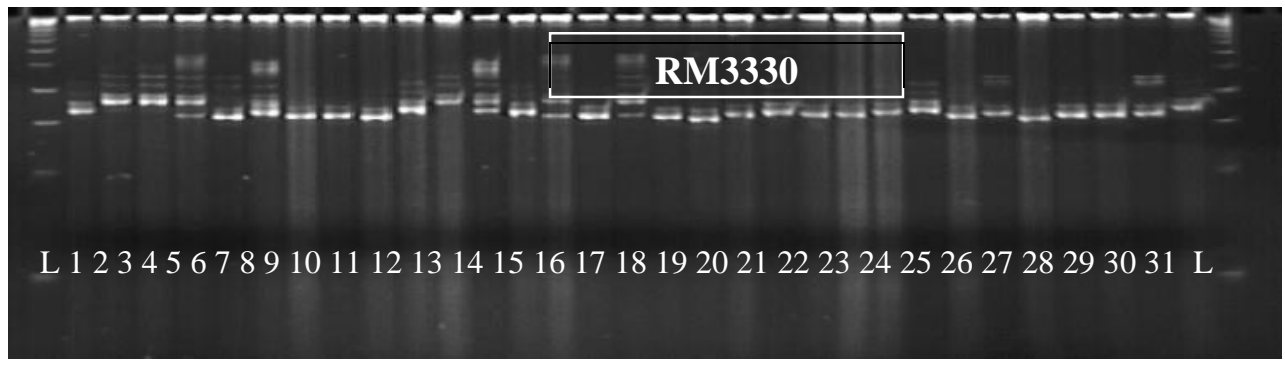

Legend: Lane 1=Begun bichi, 2=Hashikalmi, 3=Kalodhan, 4=Ausdhan, 5=Dighabawalia, 6=Hanuman jata, 7=Itcrie, 8=V-2, 9=V-3, 10=V-4, 11=Parangi, 12=Sandamioni, 13=Jaymori, 14=Kalohizli, 15= Minikit, 16= Parangi, 17= Raitul, 18=Kuchmuch, 19= Puitraaijang, 20= Boula, 21=Chaina, 22=Saithsail, 23=Sadeyaus, 24=Mallika, 25=Aduballi, 26=Bardhanaus, 27=Kaloaus, 28=Bardhanaus M-74-1, 29=H-171, 30=H-12 , 31=Kadidet.

Fig 1. DNA Profile of 31 Aus rice landraces with SSR marker RM3330.

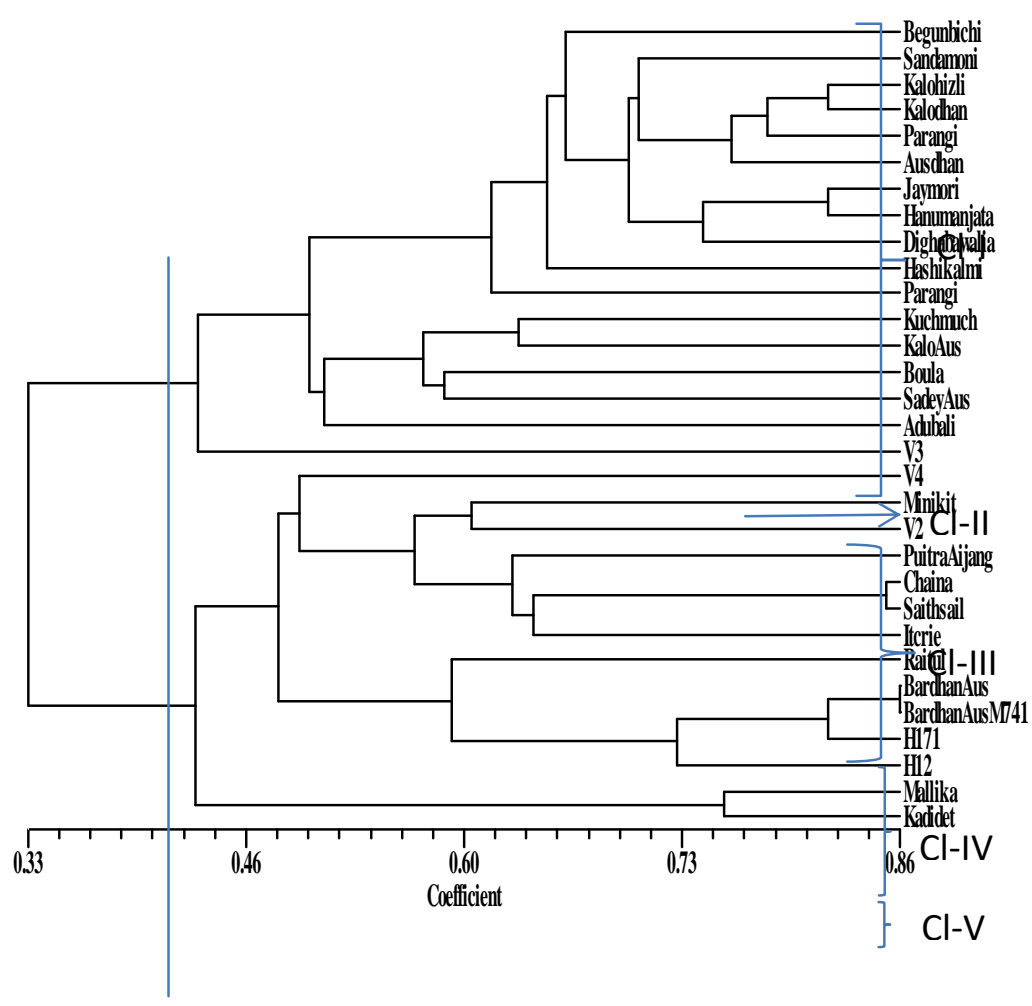

Fig. 2. A UPGMA cluster dendrogram showing the genetic relationships among 31 Aus rice genotypes based on alleles detected by 36 microsatellite markers. 


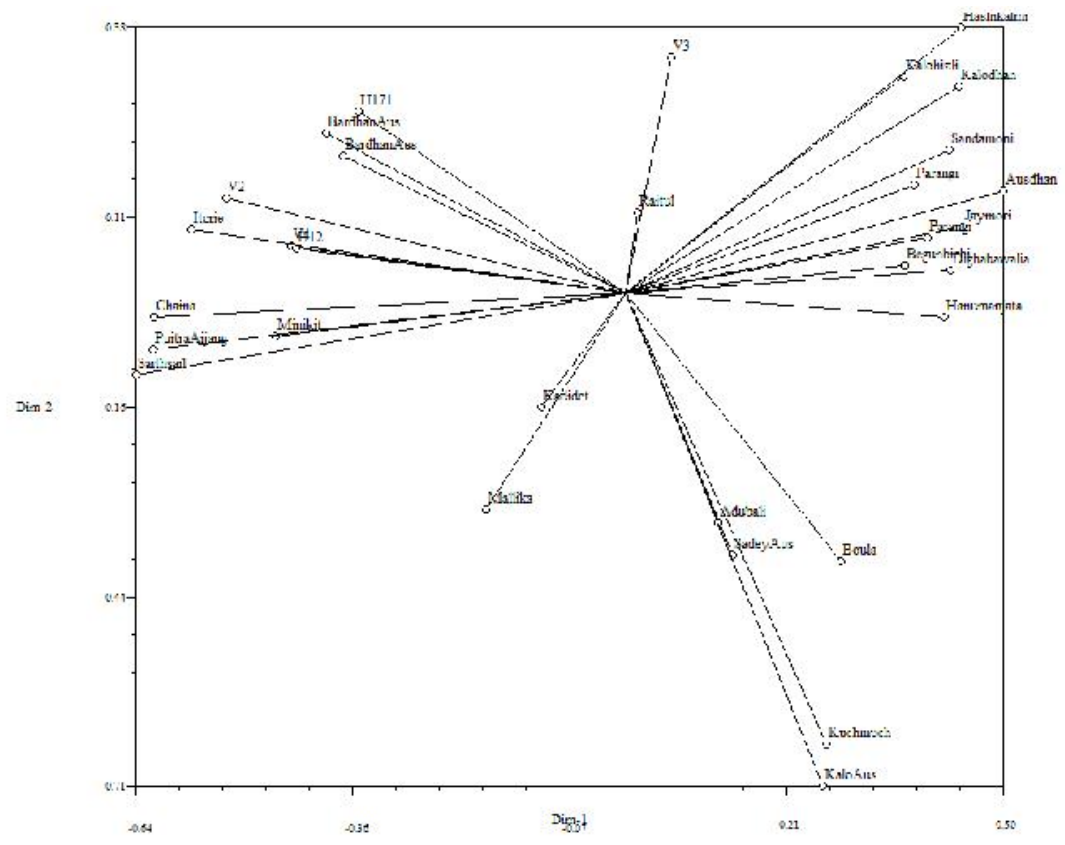

Fig.3. Two-dimensional view of principal coordinate analysis (PCoA) with 36microsatellite markers over 31 Aus rice genotypes.

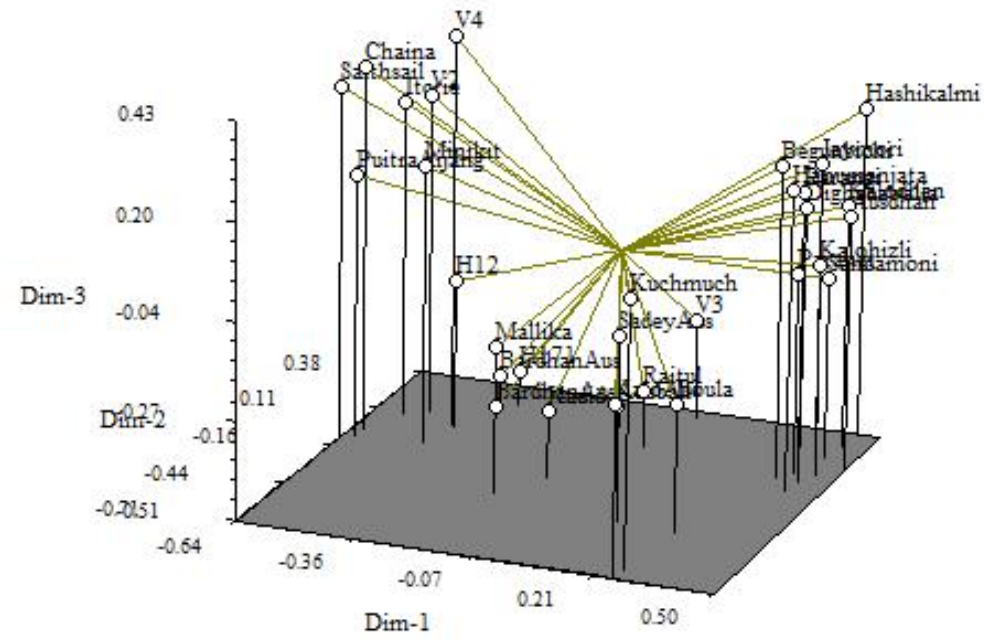

Fig.4. Three-dimensional view of principal coordinate analysis (PCoA) with 36 microsatellite markers over 31 Aus rice genotypes.

\section{Principal Coordinate Analysis}

The two and three-dimensional graphical view of Principal Coordinate Analysis (PCoA) showed the spatial distribution of the genotypes along the two and three principal axes. The genotypes Hashikalmi, Chaina, Puitraijang, Saithsail, Kuchmuch, 
Kalodhan, Ausdhan and Itcriewere found far away from centroid of the cluster and the rest of the genotypes were placed more or less around the centroid (Fig. 3 and 4). The results indicated that the genotypes were placed far away from the centroid were more genetically diverse while the genotypes were placed near around the centroid possessed more or less similar genetic background. However, centroid might define as the vector representing the middle point of the cluster that contained at least one number for each variable. The connecting lines between the each genotype and the centroid represented eigan vectors for the respective genotypes.

\section{CONCLUSIONS}

The results obtained from this study on molecular characterization provided some useful implications for establishment of sovereignty of Bangladeshi rice gene pool. Genetic diversity in any crop is important for improving heterotic crop genotypes over the existing ones. There was a high level of genetic diversity among Aus rice in this study, suggesting that SSR markers were very effective in the detection of polymorphism in this ecosystem. To broaden the genetic base and improvement of Aus rice, landraces having the lowest genetic similarities could be selected as parents. Therefore, hybridization should be made between two distant populations. Based on distance matrix, the genotypesHashikalmi, Chaina, Puitraaijang, Saithsail, Kuchmuch, Kalodhan, Ausdhan and Itcrie can be selected as parents for further breeding programs. The findings of this study should be useful for varietal identification and could help in providing guides for assisting rice breeders in selecting suitable genetically diverse parents for the crossing program.

\section{ACKNOWLEDGMENTS}

The authors are grateful to project on "Collection, characterization and promotion of rice, chili, cucumber and melon in Bangladesh" supported by AFACI (Asian Food and Agriculture Cooperation Initiative) for providing funds for this research.

\section{REFERENCES}

Akagi, H., Y. Yokozeki, A. Inagaki and T. Fujimura. 1996. Microsatellite DNA markers for rice chromosomes. Theor. Appl. Genet. 93: 1071-1077.

Allhgholipour, M., E. Farshdfar and B. Rabiei. 2014. Molecular characterization and genetic diversity analysis of different rice cultivars by microsatellite markers. Genetika. 46: 187-198.

Behera, L., B. C. Patra, R. K. Sahu, A. Nanda, S. C. Sahul, A. Patnaik, G. J. N. Rao and O. N. Singh. 2012. Assessment of genetic diversity in medicinal rices using microsatellite markers. Aus. J. Crop Sci. 6(9): 1369-1376.

BER, 2013. Bangladesh Economic Review, Ministry of Finance, Government of the People's Republic of Bangladesh, Dhaka.

Cavalli-Sforza, L. L. and A. W. F. Edwards. 1967. Phylogenetic analysis: models and estimation procedures. American J. Hum Genet. 19: 233-257.

Chakrabarthi, B. K. and R. Naravaneni. 2006. SSR marker based DNA fingerprinting and diversity study in rice (Oryza sativa L). African J. Biotech. 5(9): 684-88.

Chen, H., H. He, Y. Zou, W. Chen, R. Yu, X. Liu, Y. Yang, Y. M. Gao, J. L. Xu, L. M. Fan, Y. Li, Z. K. Li and X. W. Deng. 2011. Development and application of a set of breeder-friendly SNP markers for genetic analyses and molecular breeding of rice (Oryza sativa L.). Theor. Appl. Genet. 123: 869-879.

Choudhury, B., M. L. Khanand S. Dayanandan. 2013. Genetic structure and diversity of indigenous rice (Oryzasativa) varieties in the Eastern Himalayan region of 
Northeast India. Springer Plus.2: 228.doi: 10.1186/2193-1801-2-228. PMID: 23741655

Das, B., S. Sengupta, S. K.Parida, B. Roy, M. Ghosh and M. Prasad. 2013. Genetic diversity and population structure of rice landraces from Eastern and North Eastern States of India. BMC Genetics, 14: 71.

Garris, A. J., T. H. Tai, J. Coburn, S. Kresovich and S. McCouch. 2005. Genetic structure and diversity in Oryza sativa L. Genetics.169: 1631-1638.

HIES, 2010. Household Income and Expenditure Survey, Bangladesh Bureau of tatistics, Ministry of Planning, Government of the People's Republic of Bangladesh, Dhaka.

Islam, M. Z. 2014. Variability assessment of aromatic and fine rice (Oryza sativa L.) genotypes through morphological, physicochemical traits and microsatellite DNA markers. Gazipur, Bangladesh: Bangabandhu Sheikh Mujibur Rahman Agricultual University: 115-141.

Jain, S., R. K. Jain and S. R. McCouch. 2004. Genetic analysis of Indian aromatic and quality rice (Oryza sativa) germplasm using panels of fluorescently labeled microsatellite markers. Theor. Appl. Genet. 109: 965-977.

Jayamani, P., S. Negrao, M. Martins, B. Macas and M. M. Oliveira.2007. Genetic relatedness of Portuguese rice accessions from diverse origin as assessed by microsatellite markers. Crop Sci. 47: 879-886.

Liu, K. and S. V. Muse. 2005. Power Marker: Integrated analysis environment for genetic marker data. Bioinformatics.21: 2128-2129.

Londo, J. P., Y. C. Chiang, K. H. Hung, T. Y. Chiang and B. A. Schaal. 2006. Phylogeography of Asian wild rice, Oryza rufipogon, reveals multiple independent domestications of cultivated rice, Oryza sativa. Proc. Natl. Acad. Sci. USA 103: 9578-9583.

Lu, H., M. A. Redus, J. R. Coburn, J. N. Rutger, S. R. McCouch and T. H. Tai. 2005. Population structure and breeding patterns of 145 US rice cultivars based on SSR marker analysis. Crop Sci. 45: 66-76

Page, R. D. 1996. TreeView: an application to display phylogenetic trees on personal computers. Comput. Mol. Biol.12: 357-358.

Ramkumar, G., A. K. Biswal, K. M. Mohan, K. Sakthivel, A. K. P. Sivaranjanj, C. N. Neeraja, T. Ram, S. M. Balachandran, R. M. Sundaram and M. S. Prasad. 2010. Identifying novel alleles of rice blast resistant genes pikb and pita through allele mining. Int. Rice Res. Notes.117:185.

Rana, M. K. and K. V. Bhat. 2004. A comparison of AFLP and RAPD markers for genetic diversity and cultivar identification in cotton. J. Plant Biochem.Biotech. 13: $19-24$.

Rholf, F. 2002. NTSYS-pc: Numerical Taxonomy and Multivariate Analysis System Version 2.2. New York, USA: Department of Ecology and Evolution, State University of New York.

Saini, N., N. Jain, S. Jain and R. K. Jain. 2004. Assessment of genetic diversity within and among Basmati and non-Basmati rice varieties using AFLP, ISSR and SSR markers.Euphytica.140:133-146

Shah, S. M., S. A. Naveed and M. Arif. 2013. Genetic diversity in basmati and nonbasmati rice varieties based on microsatellite markers. Pak. J. Bot. 45: 423-431.

Siddique, M. A., M. Khalequzzaman, M. M. Islam, K. Fatema and M. A. Latif. 2016. Molecular characterization and genetic diversity in geographical indication (GI) rice (Oryzasativa L.) cultivars of Bangladesh. Braz. J. Bot. DOI 10.1007/s40415-016-0271-1. 
Siddique, M. A., E. S. M. H. Rashid, M. Khalequzzaman, M. K. Bashar and L. R. Khan. 2014. Molecular characterization and genetic diversity in T. Aman landraces of rice (Oryza sativa L.) using microsatellite markers. Thai J. Agril. Sci. 47(4): 211-220.

Singh, N., D. R. Choudhury, A. K. Singh, S. Kumar, K. Srinivasan and R. K. Tyagi. 2013. Comparison of SSR and SNP markers in estimation of genetic diversity and population structure of Indian rice varieties. PLOSone. doi: 10.1371/journal.pone. 0084136 .

Thomson, M. J., E. M. Septiningsih, F. Suwardjo, T. J. Santoso, T. S. Silitonga and S. R. McCouch. 2007. Genetic diversity analysis of traditional and improved Indonesian rice (OryzasativaL.) germplasm using microsatellite markers. Theor. Appl. Genet. 114(3): 559-568.

Thomson, M. J., N. R. Polato, J. Prasetiyono, K. R. Trijatmiko, T. S. Silitonga and S. R.McCouch.2009. Genetic diversity of isolated populations of Indonesian landraces of rice (Oryza sativa L.) collected in East Kalimantan on the Island of Borneo. Rice.2: 80-92.

Xu, X. M., K. J. Liang, S. G. Zhang, W. Sang, Y. Y. Zhang, X. N. Wei and P. Ke. 2009. Analysis of indica-japonica differentiation in rice parents and derived lines using ILP markers. Sci. Agric. Sin.42: 3388-3396. (in Chinese with English abstract)

Yadav, S., A. Singh, M. R. Singh, N. Goel, K. K. Vinod, T. Mohapatra et al. 2013. Assessment of genetic diversity in Indian rice germplasm (Oryza sativa L.): use of random versus trait-linked microsatellite markers. Journal of Genetics.92: 3. PMID: 23640403.

Zhang, P., L. Jinquan, L. Xiaoling, L. Xiangdong, Z. Xingjuan and L. Yonggen. 2011. Population structure and genetic diversity in a rice core collection (Oryza sativa L.) investigated with SSR Markers. PLOSone. 6(12): 1-13.

Zhao, X. Q., L. Yang, Y. Zheng, Z. H.Xuand W. R. Wu. 2009. Subspecies-specific intron length polymorphism markers reveal clear genetic differentiation in common wild rice (OryzarufipogonL.) in relation to the domestication of cultivated rice (O. sativaL.). J. Genet.Genom.36: 435-442.

Zheng, K., P. K. Subudhi, J. Domingo, G. Magpantay and N. Huang. 1995. Rapid DNA isolation for marker assisted selection in rice breeding. Rice Genet. Newsl. 12: 255-258. 